\title{
Hydrothermal synthesis of microalgae-derived microporous carbons for electrochemical capacitors
}

M. Sevilla, ${ }^{\mathrm{a}^{*}}$ W. Gu, ${ }^{\mathrm{b}}$ C. Falco, ${ }^{\mathrm{c}}$ M. M Titirici, ${ }^{\mathrm{d}}$ A. B. Fuertes ${ }^{\mathrm{a}}$ and G. Yushin ${ }^{\mathrm{b}^{*}}$

${ }^{\text {a }}$ Instituto Nacional del Carbón (CSIC), P.O. Box 73, 33080 Oviedo, Spain

b School of Materials Science and Engineering, Georgia Institute of Technology, Atlanta, GA, USA

c Institute for Advanced Sustainability Studies, Berliner Str 130, D-14467 Potsdam, German

${ }^{\mathrm{d}}$ Queen Mary University London, School of Materials Science \& Engineering, Mile End Road, E14NS London, UK

Corresponding author: G. Yushin: yushin@gatech.edu, phone: +1 4043853261, fax: +1 404.894.9140. M. Sevilla: martasev@incar.csic.es, phone: +34 985119090, fax: +34 985297662 


\begin{abstract}
$\mathrm{N}$-doped highly microporous carbons have been successfully fabricated from N-rich microalgae by the combination of low-cost hydrothermal carbonization and industryadopted $\mathrm{KOH}$ activation processes. The hydrothermal carbonization process was found to be an essential step for the successful conversion of microalgae into a carbon material. The materials thus synthesized showed BET surface areas in the range $\sim 1800$ $-2200 \mathrm{~m}^{2} \mathrm{~g}^{-1}$ exclusively ascribed to micropores. The carbons showed $\mathrm{N}$ contents in the $0.7-2.7$ wt. $\%$, owing to the use of N-rich microalgae as a carbon precursor. When tested in symmetric double layer capacitors (occasionally called supercapacitors) based on aqueous $\mathrm{LiCl}$ electrolytes, pseudocapacitance was only observable for the sample synthesized at the lowest temperature, $650^{\circ} \mathrm{C}$, which is the one exhibiting the largest amount of $\mathrm{N}$ - and $\mathrm{O}$-containing groups. The samples synthesized at $700-750^{\circ} \mathrm{C}$ exhibited excellent rate capability (only $20 \%$ of capacitance loose at $20 \mathrm{~A} \mathrm{~g} \mathrm{~g}^{-1}$ ), with specific capacitances of $170-200 \mathrm{~F} \mathrm{~g}^{-1}$ at $0.1 \mathrm{~A} \mathrm{~g}^{-1}$. These materials showed excellent long-term cycling stability under high current densities.
\end{abstract}

Keywords: carbon, energy storage, porosity, biomass, hydrothermal carbonization 


\section{Introduction}

Interest on electrochemical double-layer capacitors (EDLCs), also called supercapacitors, is steadily growing as part of the quest for a "greener" and more sustainable energy future. A significant part of the research is currently focused on increasing the energy stored by such devices without jeopardizing their high power density and long cycle life in order to fulfill the requirements of future systems. From the electrode material point of view, this can be achieved through the following strategies: i) tuning of the porosity to match the size of the electrolyte ions $[1,2]$, ii) introduction of heteroatoms in carbon materials $[3,4]$ and iii) use of pseudocapacitive materials such as metal oxides or conductive polymers [5-8]. By far, porous carbon materials and especially activated carbons continue to be the main choice for the construction of supercapacitors electrodes owing to the well-established fabrication procedures, relatively low cost, fairly good electronic conductivity, high chemical and thermal stability, and large surface area. Accordingly, the number of reviews devoted to the utilization of carbons materials in supercapacitors has rapidly grown in the last few years [9-17]. Recent advances in the synthesis of activated carbons have shown the possibility of fine-tuning their porosity as well as their chemical properties, thereby enhancing their performance in supercapacitors. Thus, KOH-activation has stood out among the activation procedures for allowing the synthesis of highly porous carbon materials with relatively narrow pore size distributions, being able to modulate the porosity through the control of the activation conditions, such as the amount of $\mathrm{KOH}$ used or the activation temperature [18-20]. The utilization of heteroatom-rich carbon precursors enables the direct introduction of heteroatoms/functional groups into the final product $[21,22]$, giving rise to reversible redox reactions in several electrolytes $[23,24]$. 
In terms of a sustainable and economic scalability of the production of activated carbons for supercapacitor electrodes, biomass rises as promising precursor candidate owing to its worldwide availability, renewable nature and low-cost. Microalgae, in particular, stands out for its very high photosynthesis efficiency and fast growth rate, so that its harvesting cycle is typically only 1 to 10 days, allowing a much higher turn-over than other kinds of biomasses which could be used for activated carbon production $[25$, 26] and guaranteeing thereby large availability. Furthermore, microalgae grow in adverse conditions and extreme environments (i.e. very alkaline water); therefore their cultivation does not compete for spaces employed in traditional food production [26]. Finally, the enormous biodiversity of microalgae may allow the synthesis of carbon materials with a wide range of textural and chemical characteristics. However, in spite of all those advantages and being an almost untapped resource, micro/macroalgae utilization as carbon precursor has been scarce [27-30].

On the downside, biomass heterogeneous structure makes it difficult to achieve activated carbons with uniform and batch-to-batch reproducible properties. In addition, biomass is normally characterized by low carbon yields, decreasing the overall efficiency and increasing the cost of carbon synthesis. To address these needs, low-cost, low-temperature hydrothermal carbonization has recently appeared as a procedure for homogenizing biomass, as well as removing most of the mineral matter, and increasing structure aromaticity and thereby the carbon yield. Some of us observed that direct $\mathrm{KOH}$-activation of the microalgae Spirulina Platensis leads to its complete burnout, whereas hydrothermally carbonized microalgae can be successfully converted into a highly porous carbon [31]. These attractive characteristics have spurred the utilization of hydrochar as precursor of activated carbons with high performance as supercapacitor electrodes [32-35], hydrogen stores [18] or $\mathrm{CO}_{2}$ capture sorbents [31, 36, 37]. It is 
worth noting that the hydrothermal carbonization process has risen also as an attractive procedure for producing carbon shells around metal/metal oxide nanoparticles which enhance their electrochemical performance in supercapacitors [38, 39] and Li-ion batteries [40-43].

In this work we show the successful synthesis of microalgae-derived activated carbons and their use as electrodes in supercapacitors working with an environmentally friendly neutral aqueous electrolyte, i.e. LiCl. Neutral electrolytes are gaining increasing attention as activated carbons have demonstrated a broader stability window of up to 2.2 $\mathrm{V}$ [44-48], and allowing a substantial enhancement of the energy density of the device, as $\mathrm{E}=1 / 2 \mathrm{C} \mathrm{V}^{2}$.

\section{Experimental Section}

\subsection{Preparation of activated carbons}

$\mathrm{N}$-doped hydrochar materials were obtained by hydrothermal co-carbonization of microalgae (Spirulina Platensis) and glucose mixtures, the mass ratio microalgae/glucose being 1.5 and the carbonization temperature $180^{\circ} \mathrm{C}(24 \mathrm{~h})$. After the reaction, the autoclave was allowed to cool down to room temperature, and the solid products were collected by filtration, washed with distilled water and finally dried at $110^{\circ} \mathrm{C}$ for several hours. Afterwards, the hydrochar materials were chemically activated in a vertical furnace using potassium hydroxide (Sigma-Aldrich) at temperatures in the range $650-750^{\circ} \mathrm{C}$ and $\mathrm{KOH} /$ hydrochar mass ratio of 2 . The samples were denoted as AGT, where $\mathrm{T}$ is the activation temperature in ${ }^{\circ} \mathrm{C}$. 


\subsection{Sample characterization}

Scanning electron microscopy (SEM) images were obtained on a Quanta FEG650 (FEI) instrument, whereas transmission electron microscopy (TEM) images were acquired on a JEOL (JEM-2000 EX II) microscope operating at $160 \mathrm{kV}$. The nitrogen sorption isotherms of the carbon samples were measured at $-196{ }^{\circ} \mathrm{C}$ using a Micromeritics ASAP 2020 sorptometer. The apparent surface area was calculated using the BET method; for the selection of the appropriate relative pressure range, the ISO 9277:2010 was followed [49]. The total pore volume was determined from the amount of nitrogen adsorbed at a relative pressure $\left(\mathrm{P} / \mathrm{P}_{0}\right)$ of 0.99 , whereas the micropore volume and micropore surface area were determined using the t-plot method. The average pore width, $\mathrm{L}_{0}$, was calculated by application of the equation proposed by Stoeckli and Ballerini [50]. The pore size distributions (PSD) were determined via the Quench Solid State Density Functional Theory (QSDFT) method for nitrogen [51, 52]. Elemental analysis CHN was carried out on a LECO CHN-932 microanalyzer. X-ray photoelectron spectroscopy (XPS) was carried out by means of a Thermo Scientific K-Alpha ESCA instrument using monochromatic Al-K $\alpha$ radiation $(\mathrm{hv}=1486.6 \mathrm{eV})$. Binding energies for the highresolution spectra were calibrated by setting $\mathrm{C} 1 \mathrm{~s}$ at $285.0 \mathrm{eV}$.

\subsection{Electrochemical characterization}

The electrochemical measurements were performed in symmetric beaker cells using LiCl electrolyte $(2-12 \mathrm{M})$. Gold thin foils were used as current collectors. The Celgard 2325 membrane was used as a separator. Electrodes were prepared by mixing the carbon sample and polytetrafluoroethylene (PTFE) (Aldrich, $60 \mathrm{wt} \%$ in water) as binder in weight proportion 90:10. The electrodes were dried overnight at $100^{\circ} \mathrm{C}$. The 
thickness of the electrodes was controlled at around 150-250 $\mu \mathrm{m}(11-14 \mathrm{mg}$ each electrode).

Cyclic voltammetry (CV) measurements were performed using a 1250 Galvanostat/Potentiostat (Solartron Instruments, USA) at different constant scan rates (1 - $200 \mathrm{mV} \mathrm{s}^{-1}$ ) from $-0.6 \mathrm{~V}$ to $0.6 \mathrm{~V}$. The specific gravimetric capacitance of a single electrode, $\mathrm{C}_{\mathrm{CV}}\left(\mathrm{F} \mathrm{g} \mathrm{g}^{-1}\right)$, was calculated from the area of the voltammograms using the following formula:

$$
\mathrm{C}_{\mathrm{CV}}=\frac{\int \mathrm{IdV}}{\mathrm{v} \cdot \mathrm{m} \cdot \Delta \mathrm{V}}
$$

where $I=$ current $(\mathrm{A}), v=$ scan rate $(\mathrm{V} / \mathrm{s}), \Delta V=$ voltage window $(\mathrm{V})$, and $m=$ mass (grams) of carbon material in each electrode.

Charge-discharge measurements were performed using a SCTS supercapacitor testing system (Arbin Instruments, USA) in the range of constant current densities $(0.1-20 \mathrm{~A}$ $\mathrm{g}^{-1}$ ) from $-0.6 \mathrm{~V}$ to $0.6 \mathrm{~V}$. The specific gravimetric capacitance of a single electrode, $\mathrm{C}_{\mathrm{CD}}\left(\mathrm{F} \mathrm{g}^{-1}\right)$, was deduced from the charge-discharge curves using the formula:

$$
\mathrm{C}_{\mathrm{CD}}=\frac{2 \mathrm{I}}{(\mathrm{dV} / \mathrm{dt}) \cdot \mathrm{m}}
$$

where $d V / d t=$ slope of the discharge curve $(\mathrm{V} / \mathrm{s})$.

Electrochemical impedance spectroscopy (EIS) was performed by a Gamry Reference 600 Potentiostat. Nyquist plots and frequency dependence of capacitance plots were recorded for characterization of impedance of tested samples. EIS was performed at $0 \mathrm{~V}$ within the frequency range $1 \mathrm{mHz}$ to $100 \mathrm{kHz}$ and a $10 \mathrm{mV} \mathrm{AC}$ amplitud. The specific gravimetric capacitance of a single electrode, $\mathrm{C}_{\mathrm{EIS}}\left(\mathrm{F} \mathrm{g}^{-1}\right)$, was calculated according to the following formula and normalized with respect to the specific gravimetric capacitance at $1 \mathrm{mHz}$ : 


$$
\mathrm{C}_{\mathrm{EIS}}=\frac{2 \cdot|\operatorname{Im}(\mathbf{Z})|}{2 \pi \mathrm{f} \cdot\left[(\operatorname{Im}(\mathbf{Z}))^{2}+(\operatorname{Re}(\mathrm{Z}))^{2}\right] \cdot \mathbf{m}}
$$

where $f$ is the operating frequency $(\mathrm{Hz})$, and $\operatorname{Im}(Z)$ and $\operatorname{Re}(\mathrm{Z})$ are the imaginary and real parts of the total device resistance $(\mathrm{Ohm})$.

\section{Results and discussion}

An illustration of the synthesis procedure used to produce porous carbon materials from the microalgae Spirulina Plantensis is shown in Scheme 1. These microalgae are characterized by a high protein content ( $\sim 66$ wt. $\%)$, which translates into a nitrogen content of around 11 wt. \%. Owing to their low carbohydrate content ( $\sim 19$ wt.\%), their hydrothermal carbonization is performed in the presence of glucose, which increases both hydrochar yield and $\mathrm{N}$ content, as described elsewhere [53]. During the hydrothermal carbonization, Maillard-type cascade reactions takes place between the amino groups in amino acids and the carbonyl moieties present in carbohydrates and their derivatives (e.g., HMF), increasing both carbon and nitrogen retention in the final hydrochar product, which exhibits nitrogen contents of $7-8$ wt.\%. It is worth highlighting that a complex, economic and abundant biomass such as microalgae can be used to efficiently produced $\mathrm{N}$-doped hydrochar materials instead of significantly more expensive proteins or ionic liquids $[54,55]$. As indicated in Scheme 1, the nitrogen is incorporated as aromatic heterocycles (i.e. pyrrolic-, pyridinic- and quaternary-N structures), as proved by solid-state NMR spectroscopy, XPS, and FTIR measurements elsewhere [53]. After chemical activation of the hydrochar products, the carbon materials exhibit nitrogen contents in the $0.7-2.7 \mathrm{wt} . \%$ range (Table 1 ), the amount of nitrogen decreasing with the increase of the activation temperature as a consequence of 
its preferential removal during the activation process. It should be remembered that activation with $\mathrm{KOH}$ consists of a redox reaction, where the carbon framework is etched to generate pores as a consequence of the oxidation of the carbon into carbonate ions $\left(6 \mathrm{KOH}+2 \mathrm{C} \leftrightarrow 2 \mathrm{~K}+3 \mathrm{H}_{2}+2 \mathrm{~K}_{2} \mathrm{CO}_{3}\right)$ and intercalation of the resulting potassium compounds, which are removed during subsequent washing steps [56, 57]. N-sites are electron-rich and then more sensitive to oxidation reactions, leading to their preferential removal. As shown in Figure S1, nitrogen is distributed in the activated carbons in pyridinic (398.8-398.9 eV, N-6), pyrrolic/pyridonic (400.1-400.2 eV, N-5) and quaternary (401.5 eV, N-Q) structures [58-61]. Additionally, the materials exhibit large oxygen contents, in the 14.7 - 17.9 wt.\% range (Table 1), the oxygen heteroatom being distributed in carboxylic, anhydride, lactone, ether/phenol and carbonyl/quinone groups as deduced by temperature programmed desorption (data not shown). An illustrative representation of the chemical structure of such porous carbons is provided in Scheme 1. The SEM image in Scheme 1 reveals that the N-doped activated carbons are composed of large sponge-like particles, usual for $\mathrm{KOH}$-activated hydrochar products $[18,36]$, ranging from $\sim 10$ to $150 \mu \mathrm{m}$. Those particles are highly microporous as shown by the TEM images in Figure S2 and lack graphitic ordering. As mentioned in the introduction, direct $\mathrm{KOH}$-activation of these microalgae leads to its complete burnout; therefore, the hydrothermal carbonization process holds the key for the successful conversion of algae into an advanced highly porous carbon material.

The porosity of the activated materials was examined through $\mathrm{N}_{2}$ physisorption at $-196^{\circ} \mathrm{C}$. As can be seen in Figure 1a, the $\mathrm{N}_{2}$ isotherms are type $\mathrm{I}$, typical of microporous materials. These materials exhibit a large adsorption uptake, which increases with the increase of the activation temperature. The values of apparent surface area and pore volume increase respectively from $1800 \mathrm{~m}^{2} \mathrm{~g}^{-1}\left(650{ }^{\circ} \mathrm{C}\right)$ to $\sim 2200 \mathrm{~m}^{2} \mathrm{~g}^{-1}$ 
$\left(750{ }^{\circ} \mathrm{C}\right)$ and from $0.77 \mathrm{~cm}^{3} \mathrm{~g}^{-1}\left(650^{\circ} \mathrm{C}\right)$ to $0.94 \mathrm{~cm}^{3} \mathrm{~g}^{-1}\left(750{ }^{\circ} \mathrm{C}\right)$ (see Table 1). In all the cases, the plateau is reached at $\mathrm{P} / \mathrm{P}_{0}<0.18$, which suggests pore sizes below $2 \mathrm{~nm}$ (micropore range). This is confirmed by the pore size distributions (PSDs) calculated by the QSDFT method depicted in Figure 1b, where no pores larger than $2 \mathrm{~nm}$ can be appreciated. It is worth noting that these materials are exclusively microporous even though they exhibit large surface areas and those remarkable characteristics have been obtained by a mild $\mathrm{KOH}$ activation process, i.e. $\mathrm{KOH} /$ hydrochar weight ratio $=2$.

The behavior of these materials as electrodes in supercapacitors was tested by using $\mathrm{LiCl}$ as electrolyte. We analyzed first the influence of the electrolyte concentration on electrode performance by using the AG700 sample. Figures 2a and $2 b$ reveal that, independently of the concentration of the electrolyte, the voltammograms exhibit perfect rectangular shape, even for a high sweep rate of $100 \mathrm{mV} \mathrm{s}^{-1}$ (see Figure $2 b$ ), which indicates good charge propagation along the porous structure of the material in spite of the large particle size and the presence of only micropores. The linear dependency of the specific current with the sweep rate (see Figure S3 in Supporting Information) confirms the capacitive nature of the $\mathrm{AG700}$ sample in the neutral $\mathrm{LiCl}$ electrolyte. Whereas for $\mathrm{LiCl}$ concentrations of 2 and $6 \mathrm{M}$ the voltammograms are quite similar at all sweep rates (see Figures $2 \mathrm{a}$ and $2 \mathrm{~b}$ ), indicating similar accessibility and diffusion of the electrolyte along the porous structure, for $12 \mathrm{M} \mathrm{LiCl}$ the accessibility and diffusion seems to be more restricted as denoted by the lower specific capacitance and the poorer rate performance respectively (Figure 2c). This may be due to the increased viscosity for the $12 \mathrm{M} \mathrm{LiCl}$ solution, as well as sterical hindrance caused by hydrated ions [44]. These results are also supported by the frequency response in the electrolytes of different concentration, as shown in Figure 2d. Thus, the frequency at which capacitance reaches half its maximum value is clearly lower for 2 and $6 \mathrm{M} \mathrm{LiCl}$ 
than for $12 \mathrm{M} \mathrm{LiCl}$. The fastest frequency response is provided by $6 \mathrm{M} \mathrm{LiCl}$, where saturation is achieved at $<0.05 \mathrm{~Hz}$, result that correlates well with the rate capability depicted in Figure 2c. The above results were corroborated by galvanostatic chargedischarge measurements. As can be seen in Figure 3, the AG700 sample exhibits the best rate capability in $6 \mathrm{M} \mathrm{LiCl}$, followed by $2 \mathrm{M} \mathrm{LiCl}$ and $12 \mathrm{M} \mathrm{LiCl}$, verifying the results obtained by $\mathrm{CV}$ experiments. Taking into account those results, the performance of all the materials was compared in $6 \mathrm{M} \mathrm{LiCl}$.

Figures $4 \mathrm{a}, 4 \mathrm{~b}$ and $4 \mathrm{c}$ show the cyclic voltammograms at increasing sweep rate for the different activated carbons. The CV curves of AG700 and AG750 exhibit a perfect rectangular shape even at a high sweep rate of $100 \mathrm{mV} \mathrm{s}^{-1}$, with a moderate reduction of the capacitance being registered with the increase of the sweep rate $(\sim 20$ $\%)$. This can be more clearly seen in Figure $4 \mathrm{~d}$, where the rate performance is depicted. On the other hand, the CV curves of AG650 are only rectangular for sweep rates lower than $10 \mathrm{mV} \mathrm{s}^{-1}$, with a distinguished redox bump from -0.2 to $0.2 \mathrm{~V}$. For faster sweep rates, the $\mathrm{CV}$ becomes distorted. In this case, a large capacitance decrease is registered with the increase of the sweep rate, up to $\sim 60 \%$ at $100 \mathrm{mV} \mathrm{s}^{-1}$ (Figure $4 \mathrm{~d}$ ). This behavior is likely due to its lower conductivity in comparison to AG700 and AG750, as a result of the lower carbonization temperature, delayed diffusion and current leakage as a consequence of the interaction of the numerous functional groups with the electrolyte, and the rate dependency of pseudocapacitance. Therefore, even though the presence of pseudocapacitance renders AG650 a higher capacitance per surface area at low scan rates, it is detrimental for the high rate performance of the supercapacitors.

Electrochemical impedance spectroscopy was performed to analyze the frequency response of the different porous carbons in order to get more insights into the different behavior of the various materials, especially that of AG650. Figure 5a provides 
the Nyquist plot for the different samples as well as a magnification in the highfrequency range for AG650 and AG700. Whereas the Nyquist plots of AG700 and AG750 do not show any semicircle in $\mathrm{LiCl}$ at high frequencies, that of AG650 exhibits a clear semicircle associated to charge transfer processes, in accordance with the $\mathrm{CV}$ graph. On the other hand, the Warburg region is large for AG650, pointing out resistance to the diffusion of the ions into the bulk of the particles. These results agree well with CV observations. When comparing the frequency response (Figure 5b), it can be clearly seen -also following the trend of previous results- that AG650 exhibits the slowest frequency response, $50 \%$ of capacitance being reached at a frequency of $\sim 0.05$ $\mathrm{Hz}$ (relaxation time constant, $\tau_{0} \sim 20 \mathrm{~s}$ ) in contrast to $\sim 0.2 \mathrm{~Hz}$ for AG700 and AG750 $\left(\tau_{0} \sim 5 \mathrm{~s}\right)$.

Galvanostatic charge-discharge cycling experiments were also carried out as this test provides the best representation of the real operation of a supercapacitor, demonstrating both its energy and power characteristics. The analysis of these measurements reveals trends similar to the CV and EIS experiments. As shown in Figure 6a, AG700 is the sample with the highest specific capacitance $\left(200 \mathrm{~F} \mathrm{~g}^{-1}\right.$ at $0.1 \mathrm{~A}$ $\mathrm{g}^{-1}$ ), and both AG700 and AG750 exhibit similar capacitance retention of $\sim 80 \%$ at 20 $\mathrm{A} \mathrm{g}^{-1}$. It should be noted that the specific capacitance and/or the rate capability of these materials are superior to the values reported in the literature for other porous carbons working with neutral electrolytes [44, 62-65]. Indeed, we recently reported specific capacitances in the $135-185 \mathrm{~F} \mathrm{~g}^{-1}$ in $6 \mathrm{M} \mathrm{LiCl}$ for highly porous S-containing activated carbons, although capacitance retention was better in this case owing to the greatly reduced content of bottle neck pores [62]. On the other hand, Frackowiak et al. obtained specific capacitances in the range of $\sim 110-180 \mathrm{~F} \mathrm{~g}^{-1}$ depending on the alkali metal sulfate used as electrolyte, and capacitance retention of $\sim 50 \%$ at $20 \mathrm{~A} \mathrm{~g}^{-1}$ [44]. On the 
contrary, the specific capacitance of AG650 is reduced to half its value when the current density is increased from 0.1 to $10 \mathrm{~A} \mathrm{~g}^{-1}$. The higher ESR of AG650 in comparison to AG700 and AG750 is clearly observable in Figure 6b, where a much larger IR drop is registered during charge/discharge. Finally, long-term stability studies were conducted on AG750, registering only a $2 \%$ of capacitance loose after 10000 cycles at a high current density of $10 \mathrm{~A} \mathrm{~g}^{-1}$ and 1000 cycles at $1 \mathrm{~A} \mathrm{~g}^{-1}$ (Figure 7).

Figure 8 shows the gradual enlargement of the voltage window from 0.6 to $1 \mathrm{~V}$. When the device is cycled up to $0.8 \mathrm{~V}$, the CVs exhibit near-perfect square shape, with no indication of water decomposition. However, when it is cycled between -1 and $1 \mathrm{~V}$, water reduction is observed. This leads to increase of capacitance in the $-0.6 \mathrm{~V}$ to $0.6 \mathrm{~V}$ range. However, when the material is cycled again between -0.6 and $0.6 \mathrm{~V}$, the voltammogram superimposes to the original one, indicating that the modification of the material (either carbon functionalization or access to the smaller pores as a consequence of the higher voltage window) is completely reversible. In this way, the specific capacitance of the material becomes $156 \mathrm{~F} \mathrm{~g}^{-1}$ when it is cycled up to $0.8 \mathrm{~V}$, whereas it increases to $185 \mathrm{~F} \mathrm{~g}^{-1}$ when it is charged up to $1 \mathrm{~V}$ window (pseudocapacitance arising from hydrogen electrosorption plus possible reversible oxidation of the material/enhanced double-layer formation), decreasing again to $156 \mathrm{~F} \mathrm{~g}^{-1}$ when it is cycled below $0.8 \mathrm{~V}$. At this point, it is worth noting that such enlargement of the voltage window from 0.6 to $1 \mathrm{~V}$ would allow almost tripling the energy density of the device without detrimental effects on its long-term performance.

\section{Conclusions}

In summary, we have shown a successful procedure for the synthesis of $\mathrm{N}$-doped highly microporous carbon materials from a microalgae - a renewable, economically-viable and widely available precursor. This procedure is based on the combination of 
hydrothermal carbonization and chemical activation processes, where the hydrothermal carbonization process holds the key for the success. These carbon materials combine large surface areas up to $\sim 2200 \mathrm{~m}^{2} \mathrm{~g}^{-1}$ and an exclusively microporous structure. The use of N-rich microalgae allowed additional N-doping of the final porous carbon materials $(0.7-2.7 \mathrm{wt} . \%)$. When tested in symmetric supercapacitors working with neutral aqueous $\mathrm{LiCl}$ electrolyte, the porous carbons synthesized at $\mathrm{T}=700-750{ }^{\circ} \mathrm{C}$ exhibit excellent rate capability, $80 \%$ of the capacitance being retained at a current density of $20 \mathrm{~A} \mathrm{~g}^{-1}$. Long-term cycling further shows the excellent stability of the prepared supercapacitors, even for cycling at high current densities (10 $\left.\mathrm{A} \mathrm{g} \mathrm{g}^{-1}\right)$. Pseudocapacitance is only observed for the sample synthesized at the lowest temperature, i.e. $650{ }^{\circ} \mathrm{C}$, which is the one with the largest amount of nitrogen and oxygen functionalities.

\section{Acknowledgements}

The financial support for this research work provided by the US Army Research Office (grant W911NF-12-1-0259) and by the Spanish MINECO (MAT2012-31651) is gratefully acknowledged. M.S. thanks the Spanish MINECO for the award of a Ramón y Cajal contract.

\section{References}

[1] J. Chmiola, G. Yushin, Y. Gogotsi, C. Portet, P. Simon, P.L. Taberna, Science, 313 (2006) 1760-1763.

[2] E. Raymundo-Piñero, K. Kierzek, J. Machnikowski, F. Béguin, Carbon, 44 (2006) 2498-2507.

[3] V. Ruiz, C. Blanco, E. Raymundo-Piñero, V. Khomenko, F. Béguin, R. Santamaría, Electrochim. Acta, 52 (2007) 4969-4973.

[4] M. Seredych, D. Hulicova-Jurcakova, G.Q. Lu, T.J. Bandosz, Carbon, 46 (2008) 1475-1488.

[5] G.A. Snook, P. Kao, A.S. Best, J. Power Sources, 196 (2011) 1-12.

[6] G. Wang, L. Zhang, J. Zhang, Chem. Soc. Rev., 41 (2012) 797-828.

[7] C.D. Lokhande, D.P. Dubal, O.-S. Joo, Current Applied Physics, 11 (2011) 255-270.

[8] W. Deng, X. Ji, Q. Chen, C.E. Banks, RSC Adv., 1 (2011) 1171-1178.

[9] L.L. Zhang, Y. Gu, X.S. Zhao, J. Mater. Chem. A, 1 (2013) 9395-9408. 
[10] A. Ghosh, Y.H. Lee, ChemSusChem, 5 (2012) 480-499.

[11] M. Inagaki, H. Konno, O. Tanaike, J. Power Sources, 195 (2010) 7880-7903.

[12] Y. Zhai, Y. Dou, D. Zhao, P.F. Fulvio, R.T. Mayes, S. Dai, Adv. Mater., 23 (2011) 4828-4850.

[13] L.L. Zhang, X.S. Zhao, Chem. Soc. Rev., 38 (2009) 2520-2531.

[14] L. Wei, G. Yushin, Nano Energy, 1 (2012) 552-565.

[15] J. Wang, S. Kaskel, J. Mater. Chem., 22 (2012) 23710-23725.

[16] P. Kalyani, A. Anitha, Int. J. Hydrogen Energy, 38 (2013) 4034-4045.

[17] W. Gu, G. Yushin, WIREs Energy Environ, doi: 10.1002/wene.102 (2013).

[18] M. Sevilla, A.B. Fuertes, R. Mokaya, Energy Environ. Sci., 4 (2011) 1400-1410.

[19] D. Lozano-Castelló, D. Cazorla-Amorós, A. Linares-Solano, Fuel Process. Technol., 77-78 (2002) 325-330.

[20] A. Castro-Muñiz, F. Suárez-García, A. Martínez-Alonso, J.M.D. Tascón, T. Kyotani, ChemSusChem, 6 (2013) 1406-1413.

[21] M. Sevilla, A.B. Fuertes, Microp. Mesop. Mater., 158 (2012) 318-323.

[22] L. Wei, M. Sevilla, A.B. Fuertes, R. Mokaya, G. Yushin, Adv. Funct. Mater., 22 (2012) 827834.

[23] L. Zhao, L.-Z. Fan, M.-Q. Zhou, H. Guan, S. Qiao, M. Antonietti, M.-M. Titirici, Adv. Mater., 22 (2010) 5202-+.

[24] W. Xiong, M. Liu, L. Gan, Y. Lv, Z. Xu, Z. Hao, L. Chen, Colloids Surf., A, 411 (2012) 34-39.

[25] M. Frac, S. Jezierska-Tys, J. Tys, Afr. J. Biotechnol., 9 (2010) 9227-9236.

[26] J. Singh, S. Gu, Renew. Sust. Energ. Rev., 14 (2010) 2596-2610.

[27] R. Aravindhan, J. Raghava Rao, B. Unni Nair, J. Hazard. Mater., 162 (2009) 688-694.

[28] S. Altenor, M.C. Ncibi, E. Emmanuel, S. Gaspard, Biochem. Eng. J., 67 (2012) 35-44.

[29] A. Rathinam, J.R. Rao, B.U. Nair, J. Taiwan Inst. Chem. E., 42 (2011) 952-956.

[30] E. Raymundo-Piñero, M. Cadek, F. Béguin, Adv. Funct. Mater., 19 (2009) 1032-1039.

[31] M. Sevilla, C. Falco, M.-M. Titirici, A.B. Fuertes, RSC Adv., 2 (2012) 12792-12797.

[32] L. Wei, M. Sevilla, A.B. Fuertes, R. Mokaya, G. Yushin, Adv. Energy Mater., 1 (2011) 356361.

[33] C. Falco, J. Manuel Sieben, N. Brun, M. Sevilla, T. van der Mauelen, E. Morallon, D. CazorlaAmoros, M.-M. Titirici, ChemSusChem, 6 (2013) 374-382.

[34] H. Wang, Z. Li, J.K. Tak, C.M.B. Holt, X. Tan, Z. Xu, B.S. Amirkhiz, D. Harfield, A. Anyia, T. Stephenson, D. Mitlin, Carbon, 57 (2013) 317-328.

[35] H. Wang, Z. Xu, A. Kohandehghan, Z. Li, K. Cui, X. Tan, T.J. Stephenson, C.K. King'ondu, C.M.B. Holt, B.C. Olsen, J.K. Tak, D. Harfield, A.O. Anyia, D. Mitlin, ACS Nano, 7 (2013) 51315141.

[36] M. Sevilla, A.B. Fuertes, Energy Environ. Sci., 4 (2011) 1765-1771.

[37] Z. Zhang, K. Wang, J.D. Atkinson, X. Yan, X. Li, M.J. Rood, Z. Yan, J. Hazard. Mater., 229230 (2012) 183-191.

[38] H. Zheng, T. Zhai, M. Yu, S. Xie, C. Liang, W. Zhao, S.C.I. Wang, Z. Zhang, X. Lu, Journal of Materials Chemistry C, 1 (2013) 225-229.

[39] J. Liu, S. Liu, S. Zhuang, X. Wang, F. Tu, lonics, 19 (2013) 1255-1261.

[40] S.-J. Park, Y.-J. Kim, H. Lee, J. Power Sources, 196 (2011) 5133-5137.

[41] M. He, L. Yuan, X. Hu, W. Zhang, J. Shu, Y. Huang, Nanoscale, 5 (2013) 3298-3305.

[42] X.W. Lou, J.S. Chen, P. Chen, L.A. Archer, Chemistry of Materials, 21 (2009) 2868-2874.

[43] G. Fang, S. Kaneko, W. Liu, B. Xia, H. Sun, R. Zhang, J. Zheng, D. Li, Applied Surface Science, 283 (2013) 963-967.

[44] K. Fic, G. Lota, M. Meller, E. Frackowiak, Energy Environ. Sci., 5 (2012) 5842-5850.

[45] M.P. Bichat, E. Raymundo-Piñero, F. Béguin, Carbon, 48 (2010) 4351-4361.

[46] L. Demarconnay, E. Raymundo-Piñero, F. Béguin, Electrochemistry Communications, 12 (2010) 1275-1278.

[47] Y.-K. Hsu, Y.-C. Chen, Y.-G. Lin, L.-C. Chen, K.-H. Chen, J. Mater. Chem., 22 (2012) 33833387. 
[48] X. Yang, Y.-S. He, G. Jiang, X.-Z. Liao, Z.-F. Ma, Electrochemistry Communications, 13 (2011) 1166-1169.

[49] in, Geneva, 2012.

[50] F. Stoeckli, L. Ballerini, Fuel, 70 (1991) 557-559.

[51] A.V. Neimark, Y. Lin, P.I. Ravikovitch, M. Thommes, Carbon, 47 (2009) 1617-1628.

[52] P.I. Ravikovitch, A.V. Neimark, Langmuir, 22 (2006) 11171-11179.

[53] C. Falco, M. Sevilla, R.J. White, R. Rothe, M.M. Titirici, ChemSusChem, 5 (2012) 1834-1840.

[54] N. Baccile, M. Antonietti, M.M. Titirici, ChemSusChem, 3 (2010) 246-253.

[55] P. Zhang, J. Yuan, T.-P. Fellinger, M. Antonietti, H. Li, Y. Wang, Angew. Chem. Int. Ed., 52 (2013) 6028-6032.

[56] M.A. Lillo-Ródenas, D. Cazorla-Amorós, A. Linares-Solano, Carbon, 41 (2003) 267-275.

[57] M.A. Lillo-Ródenas, J. Juan-Juan, D. Cazorla-Amorós, A. Linares-Solano, Carbon, 42 (2004) 1371-1375.

[58] F. Kapteijn, J.A. Moulijn, S. Matzner, H.P. Boehm, Carbon, 37 (1999) 1143-1150.

[59] K. Stańczyk, R. Dziembaj, Z. Piwowarska, S. Witkowski, Carbon, 33 (1995) 1383-1392.

[60] J.R. Pels, F. Kapteijn, J.A. Moulijn, Q. Zhu, K.M. Thomas, Carbon, 33 (1995) 1641-1653.

[61] K. Stańczyk, Energy \& Fuels, 18 (2004) 405-409.

[62] W. Gu, M. Sevilla, A. Magasinski, A.B. Fuertes, G. Yushin, Energy Environ. Sci., 6 (2013) 2465-2476.

[63] S.-E. Chun, J.F. Whitacre, Electrochim. Acta, 60 (2012) 392-400.

[64] J.-w. Lang, X.-b. Yan, W.-w. Liu, R.-t. Wang, Q.-j. Xue, J. Power Sources, 204 (2012) 220229.

[65] E.G. Calvo, F. Lufrano, P. Staiti, A. Brigandì, A. Arenillas, J.A. Menéndez, J. Power Sources, 241 (2013) 776-782. 


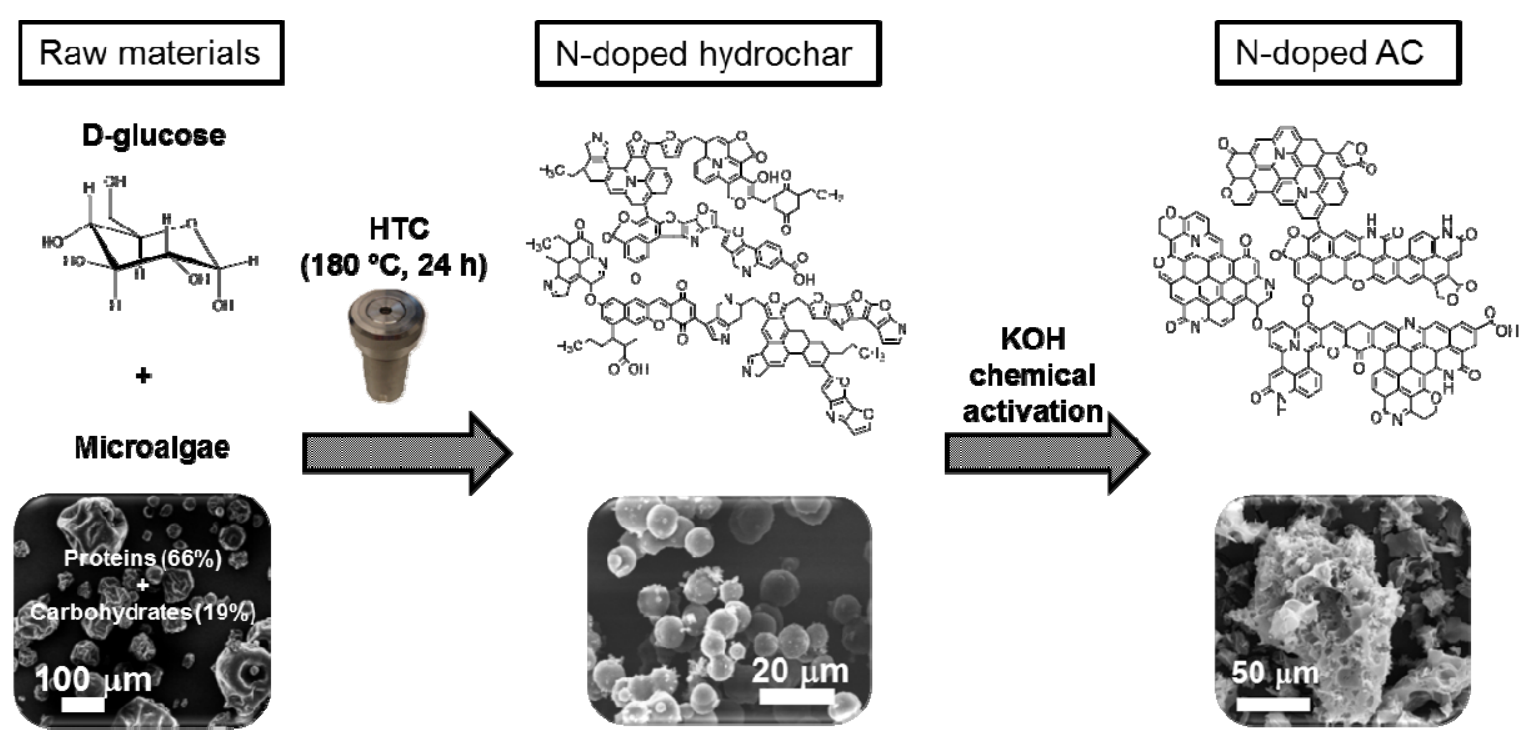

Scheme 1. Schematic of the porous carbon synthesis from a mixture of microalgae and glucose. 